\title{
EL CORREO ESPAÑOL DE BUENOS AIRES. UNA LECTURA SOCIAL SOBRE EL NACIONALISMO ESPAÑOL Y LA CONSTRUCCIÓN ASOCIATIVA DESDE EL PERIÓDICO (1872-1905)
}

Marcelo Hugo Garabedian ${ }^{1}$

RESUMO: Nossa proposta neste trabalho será estudar as alternativas utilizadas por El Correo Español (doravante ECE) para projetar uma identidade nacional espanhola na diáspora. Vamos rever nesta apresentação são apenas duas alternativas desse desenvolvimento: ECE como um construtor e contador de uma história própria totalmente desenvolvida na diáspora e, em segundo lugar, o uso da língua castelhana como uma portadora de identidade e cultura. Nós acreditamos que esta ação foi imprescindível para a construção de um "coletivo" espanhol em Buenos Aires, que foi acompanhada das atividades do movimento associativo espanhol, culminando por definir uma identidade que se diferencia dos outros grupos migrantes, e por sua vez uma identificação frente às elites da sociedade receptora.

PALAVRAS-CHAVE: Nacionalismo Espanhol. Construção Associativa. Jornal.

RESUMEN: Nuestra propuesta en este trabajo será la de estudiar las alternativas utilizadas por El Correo Español (en adelante ECE) para proyectar una identidad nacional española en la diáspora. Nosotros repasaremos en esta presentación solo dos

1 Magister en Investigación en Cs. Sociales, Lic. Ciencia Política y Profesor en Cs. Sociales (UBA). Doctor en Historia (UTDT). Investigador Museo Roca, Instituto de Investigaciones Históricas, Ministerio de Cultura de la Nación. Docente Universidad de Buenos Aires y Universidad Nacional de José C. Paz. 
alternativas de este desarrollo: ECE como constructor y narrador de una historia propia desarrollada íntegramente en la diáspora $y$, en segundo lugar, el uso del idioma castellano como portador de identidad y cultura. Creemos que esta acción fue una tarea imprescindible para la construcción de un "colectivo" español en Buenos Aires, que acompañada a su vez de las actividades del movimiento asociativo español, culminaron por definir una entidad que se diferenciara de otros colectivos migrantes, y a su vez una identificación ante las élites de la sociedad receptora.

PALAVRAS-CHAVE: Nacionalismo español. Construcción asociativa. Periódico.

ABSTRACT: Our proposal in this work will be to study the alternatives used by El Correo Español (ECE) to project a Spanish national identity in the diaspora. We will review in this presentation only two alternatives of this development: ECE as constructor and narrator of a proper history developed entirely in the diaspora and, secondly, the use of the Castilian language as a bearer of identity and culture. We believe that this action was an essential task for the construction of a Spanish "collective" in Buenos Aires, which, together with the activities of the Spanish associative movement, culminated in defining an entity that was different from other migrant groups, and in turn An identification with the elites of the receiving society.

KEYWORDS: Spanish nationalism. Associative construction. Newspaper. 


\section{Introducción}

El Correo Español de Buenos Aires publicó su primer ejemplar el 29 de julio de 1872. Su fundador y primer director fue el exiliado republicano y ex canónigo malagueño Enrique Romero Jiménez.

Sin dudas, ECE fue el periódico más importante del último cuarto del siglo XIX extendiéndose desde 1872 hasta el año 1905. Durante su dilatada existencia se sucedieron cuatro directores propietarios: Romero Jimenez desde su fundación hasta el año 1880, Justo López de Gomara (1880 - 1890), Rafael Calzada (1890 - 1892) y su último director propietario fue Fernando López Benedito (1892 - 1903). A partir de 1903, ECE se transformó en Sociedad Anónima hasta su desaparición definitiva ocurrida en octubre de 1905. El Presidente de la Sociedad Anónima fue el Dr. Rafael Calzada y durante esta etapa se sucedieron tres directores periodísticos: Fernando López Benedito, Ricardo Fuente y el último en ocupar ese cargo fue Salvador Alfonso.

Al momento de su aparición, se contabilizaban aproximadamente unos veinticinco mil españoles residentes en la ciudad. Cuando el periódico cesó sus actividades, los datos del Primer Censo Municipal de la Ciudad de Buenos Aires de 1904 dieron cuenta de la existencia de más de cien mil inmigrantes españoles en Buenos Aires. Este crecimiento de la inmigración acompañó la ampliación de los límites geográficos y urbanísticos de la ciudad capital argentina, vigorizando el aumento del sector mercantil y fabril que comenzaban a moldear la fisonomía porteña, otorgándole su impronta de urbe "mercantil y administrativa", como afirmaba James Scobie. Volviendo al censo de 1904, la participación de la inmigración en el comercio y en el sector propietario de inmuebles fue significativo. La participación de los españoles entre los comerciantes minoristas y medianos fue muy importante. Si bien no es el objetivo de esta presentación, queremos dejar asentado, para contar con una idea estimativa de su alcance e influencia social, que el crecimiento en la tirada de ECE tuvo su principal explicación en el crecimiento de este sector social de pequeños y medianos comerciantes, una burguesía mercantil muy arraigada y con fuertes vínculos con sus instituciones 
más representativas. Si en 1872 ECE imprimía alrededor de mil ejemplares, para el cambio de siglo, según nos informa el propio periódico, su tirada ascendía a los cuarenta mil ejemplares.

Tomando en consideración su extensión dentro de la colonia de españoles residentes en la ciudad, creemos necesario indagar en los procesos de construcción social y política que el periódico ayudó a constituir, no sólo como un emisor de discursos, sino también como uno de los actores principales a la hora de crear ese "lazo social" tan vindicado entre los protagonistas de la época.

\section{Preludio: la complejidad de la identidad nacional española durante el siglo XIX y sus desafíos.}

Los historiadores consultados acerca de la construcción de la nacionalidad española giran en torno a una idea común: el escaso desarrollo que conoció el nacionalismo español en la península durante la segunda mitad del siglo XIX. ${ }^{2}$

Siguiendo al historiador Núñez Seixas, fue una tarea muy difícil lograr la figura de un nosotros en España, y en contraposición, sí podrían encontrarse nacionalismos periféricos que se vigorizaron a partir del último cuarto del siglo XIX. En este aspecto, tanto en la península como en la diáspora, la puja entre los nacionalismos estaba planteada en los términos en una lucha de "suma cero", en el sentido que el avance de un nacionalismo implicaba necesariamente el retraimiento del otro. ${ }^{3}$

2 Los autores consultados fueron: ALVAREZ JUNCO, José. Mater dolorosa. La idea de España en el siglo XIX. Madrid: Taurus, 2001; PORTILLO VALDÉS, José María. Nación. En: FERNÁNDEZ SEBASTIÁN, Javier; FUENTES, Juan Francisco (dirs.). Diccionario político y social del siglo XIX español. Madrid: Alianza Editorial, 2002. p. 468-476; INMAN-FOX, Edward. La invención de España. Nacionalismo liberal e identidad nacional. Madrid: Cátedra, 1997; NÚÑEZ SEIXAS, Xosé Manoel. Los nacionalismos en la España Contemporánea (siglos XIX y XX). Barcelona: Hipótesis, 1999; REVISTA HISTORIA SOCIAL. Valencia, n. 40, 2001. Número especial La construcción imaginaria de las comunidades nacionales.

3 NÚÑEZ SEIXAS, op. cit., p. 28. 
Sin embargo, y a pesar de estas carencias, la empresa de construir una identidad nacional tuvo en el siglo XIX una serie de líneas históricas que comenzaron a sistematizarse y a desarrollarse no solo en el campo de la historia, sino también en la construcción de símbolos e imágenes histórico políticas, y también en el ámbito de las artes, sobre todo en la pintura y en la literatura.

Un dato no menor que también marcó la construcción de un imaginario de los españoles, fueron los viajeros foráneos que dejaron una crónica de un país casi sin industrias, con altas tasas de analfabetismo y de pobreza. Sumado a ello, encontramos en Francia y su discurso anti hispanófilo a un otro exterior, que vinculaba a España con el oscurantismo y el fanatismo religioso. Son éstas las ideas que se combatirán desde la prensa, y que comenzaron a formar parte de un nosotros.

Una de las preocupaciones más importantes fue mostrar a España como un país moderno, cuyo significado era poseer industrias, ciencia propia y exhibir un crecimiento económico que la colocara a la altura de las naciones más importantes de Europa. Para ello ECE reprodujo en sus páginas las informaciones que colocaran al país en la senda del progreso y a su vez, insertaba en sus planas la narración de una historia nacional con eje en Castilla. A continuación, analizaremos lo que nosotros comprendemos como un necesario trabajo de complementación a esta idea: una historia narrada desde propia experiencia en la diáspora a través de las figuras locales.

\section{ECE como constructor de imágenes y discursos nacionales subjetivos}

No todo era, por otra parte, cuestión de doctrina o principios. También había que suscitar emociones. Lograr la identificación y la lealtad de los individuos hacia la nación requería de un esfuerzo previo de imaginación que convirtiese en visible esa personalidad colectiva a la que tanto poder se atribuía. (ALVAREZ JUNCO, 2001, p. 193). 
Esta idea expuesta por Alvarez Junco podría muy bien aplicarse a las hipótesis que intentará encerrar esta sección del trabajo. Aquí desplegaremos una serie de argumentos basados en hechos concretizados por el periódico y por aquellos intelectuales emigrados esmerados por crear una comunidad local, sobre la base y nutridos en parte por los discursos e ideas estado céntricas provenientes de las instituciones con sede en Madrid que ECE reprodujo como un insumo principal. Pero en cierta forma, y por el mismo sendero que nos marca Alvarez Junco, esto no era suficiente, y así lo entendieron tanto los redactores del diario, como la elite dirigente de las asociaciones españolas.

En la medida en que otros paisanos se movilizaran por causas, en principio no directamente vinculadas con la cuestión nacional, se acentuaba la idea de la existencia de un "lazo de unión”. Esta frase, ampliamente aludida en la época, se transformó en el objetivo a perseguir por las asociaciones y por los periódicos españoles y regionales que participaban en el escenario del periodismo rioplatense. La comunión de sujetos movilizados por causas conexas al nacionalismo, pero no directamente vinculadas, daba la idea de un conjunto de sujetos que adquirían cierta conciencia de sí y para sí en tanto se sentían interpelados por discursos e imágenes, y por la retórica de quien se siente lejano de su patria, pero muy cercano a otros individuos permeados por las mismas experiencias de vida y llevados de los mismos intereses.

Creemos necesario abordar este punto focalizando sobre todo en la subjetividad de los individuos, quienes participaban de las iniciativas que impulsaba ECE y las asociaciones, movidos sobre todo no por los grandes discursos nacionales, exteriores a su agencia, sino por aquellas que hicieron vibrar los valores y sentimientos que también formaban parte de su identidad, en tanto inmigrantes en una sociedad que no era su patria.

Aquí repasaremos aquellos pasajes de la vida del diario en donde nosotros creemos corroborar estas acciones, sumado también a otras características del periódico que contribuyeron a formar un "nacionalismo español en la diáspora", donde además de las instituciones y asociaciones representativas, se contó 
también con figuras locales y una historia propia, realizada en el seno de la sociedad receptora y lejos de la península, efemérides en principio privadas y personales, pero que fueron colocadas como un faro, o más exactamente, un canon específico, que otorgaba legitimidad en una sociedad que carecía de valores nobiliarios o estamentales, y por lo tanto, accesible a todos los paisanos que intentaran el camino del éxito personal, y vincularse a otros migrantes, en tanto "españoles".

\section{La construcción de un colectivo en la diáspora y los aportes a una historia local común. El canon del "inidiano exitoso"}

En verdad que tan sublime espectáculo hubiera arrancado lágrimas de ardiente regocijo a los fundadores e iniciadores de la Sociedad de Beneficencia, el brillante D. Vicente Rosa, el filántropo Esteban Rams y Rubert, el periodista D. Benito Hortelano y el generoso D. Pedro Manuel de la Bárcena, si por maravilloso artificio hubieran levantado la loza que cubre al presente sus mortales restos. (CARRILLO SÁNCHEZ, 1887, p. 30).

¿Cuáles fueron los itinerarios que llevaron a todos estos "notables españoles" a convertirse en patriarcas de la colonia española rioplatense? Develar estos principios será pues parte de la tarea de este apartado.

El fragmento citado anteriormente pertenece a la obra Galería de los Españoles Notables de Rafael Carrillo Sánchez, publicada en Buenos Aires en el año 1887 por la "Imprenta, Litografía y Encuadernación de Stiller \& Laars", ubicada en la calle San Martín 169. Esta edición contaba con 164 páginas, en donde además de las biografías de Don Juan Durán y Cuerbo, representante diplomático de España en Argentina, José P. de Carabasa, un importante banquero de la plaza porteña, Salvador Gómez Gómez, un comerciante y hombre ligado a los negocios que recorrió un itinerario diferente al resto de los biografiados, puesto que hizo su fortuna en los Estados Unidos, para luego recorrer los destinos sudamericanos y afincarse en Buenos Aires. 
El último de la lista de "españoles notables" fue Justo Sanjurjo López de Gomara, en ese momento Director de ECE. Además de las cuatro biografías, la Galería emprende la tarea de dar cuenta de la historia de la consolidación institucional de los españoles en Buenos Aires. Para ello, el autor recurre a testimonios orales de otros paisanos protagonistas de la época, de familiares y amigos, utiliza la autobiografía de Benito Hortelano, y como él mismo cuenta, se apoya en la colaboración de López de Gomara. Quizás el aporte más importante haya sido la convocatoria a otros paisanos, para que se acercaran a contar sus propias experiencias, lo que los interpelaba en tanto protagonistas de la historia que narraban, situándolos dentro de la misma, y no como observadores externos.

La Galería de los Españoles notables abarca todas las instituciones necesarias para que se pudiera hablar, según los parámetros de la época, de una colonia en extraño suelo. La historia reseñada necesariamente abarcaba la Sala Española de Beneficencia, los orígenes de la idea y posterior consecución del Hospital Español, la Asociación Española de Socorros Mutuos, el Club Español, otras asociaciones regionales, y por supuesto, los periódicos como un elemento fundamental a la hora de establecer una colonia.

La obra de Carrillo Sánchez fue, hasta donde nos fue posible indagar, la primera en su tipo en la ciudad de Buenos Aires. Fue un emprendimiento que se realizó por fuera y de manera independiente de ECE, pero que nuestro periódico anunció desde sus páginas con el título "Galería de los Españoles notables del Río de la Plata". ${ }^{4}$ El periódico informaba:

Con este título va a empezar a publicarse una obra interesantísima, que comprende la historia de la colectividad española en la República Argentina, desde la caída de Rosas y las biografías de

4 No sabemos si se trató de un error o de un repentino cambio de planes, pero la obra se tituló sólo Galería de los Españoles notables y se refirió sólo a las instituciones y biografías radicadas en la ciudad de Buenos Aires. 
todos los españoles que se han formado una posición digna en esta y la vecina república. ${ }^{5}$

Este libro es, a nuestro criterio, el primer intento sistematizado que buscó reflejar la historia institucional de la colonia y la de sus miembros más sobresalientes. Al igual que la Galería de los Españoles Ilustres, entendemos este trabajo de Carrillo Sánchez como una construcción de una escala inferior, que se apoyaba sobre los discursos y representaciones nacionales, pero que lo despliega a partir de una microhistoria, de la que sus miembros son reflejos, con nombre y apellido, de esa identidad española declamada desde las páginas de la prensa de los inmigrantes españoles y desde las producciones bibliográficas.

Al día siguiente del anuncio, ECE publicó el prospecto de la obra, acción anterior al comienzo de las suscripciones para adquirir la Galería. Allí el autor explicó el propósito y los alcances que lo llevaron a emprender esta recopilación. Al respecto, y con una claridad notable, Carrillo Sánchez decía:

Hasta hoy ha podido prescindirse de esta clase de trabajos: nuestro mismo aislamiento y la inconsistencia de nuestras relaciones con los gobiernos de la madre patria, los hubiera hecho infecundo. Pero a medida que nuestro número aumenta, que las grandes líneas de la política internacional de España empiezan a dibujarse con firmeza y claridad; que la comunicación oficial con sus gobiernos se hace mas intima y directa, y que los lazos que nos unen individual y colectivamente se anudan, y consolidan, son de todo punto indispensables. Necesitamos conocernos y que se nos conozca, para apreciarnos como es debido y que senos aprecie como merecemos. [...] ya no somos un conjunto aislado de individuos con propósitos puramente personales: desempeñamos además, una misión oficial, constituimos uno de los resortes de la administración pública de nuestra patria, y desde este punto de vista, ni los

5 GALERÍA de los Españoles notables del Río de la Plata. ECE, Buenos Aires, p. 2, C1, 2 jul. 1887. El subrayado es nuestro. 
esfuerzos de nuestro patriotismo resultarán estériles, ni nuestros nombres se perderán en el olvido. La historia irá recogiendo los que sean dignos de sus páginas. ${ }^{6}$

La distancia que media entre la llegada de un inmigrante anónimo al momento de desembarcar del viejo Puerto de Buenos Aires hasta convertirse en una referencia para sus pares, muchos años después, se erige en un objeto de estudio, por cuanto las acciones que mediaron entre estos polos, dieron cuenta de una construcción, tanto de ECE, como de aquellos miembros de la elite intelectual que, como Carillo Sánchez, resaltaron la significación de aquellos primeros hombres que desplegaron iniciativas para la sociabilidad española. Al mismo tiempo que evocaban a estas figuras, pero sobre todo a la ubicación social de éstos en tanto status y prestigio, reforzaron simultáneamente su propia posición y su propio rol, frente a la "masa" de inmigrantes que los reconocen como individuos que han logrado una figuración y reconocimiento, fronteras adentro y por fuera de la colonia a la que se pretendía representar. Estos sujetos, los notables, fijaron referencias, marcaron itinerarios y establecieron ciertos valores: el canon del indiano exitoso:

así iban desapareciendo esa pléyade de españoles que pueden ponerse en línea con los Rosa, los Rams y Rubert, los Hortelano, los Casares, los Ayerza y tantos otros que, cual faros luminosos, han alumbrado con resplandores vivísimos el camino que habíamos de recorrer luego los que les hemos sucedido: el camino del bien, del compañerismo, de la fraternidad. (CARRILLO SÁNCHEZ, 1887, p. 38, el subrayado es nuestro).

Un segundo intento de sistematización podemos encontrarlo en ECE en el año 1903, a partir de una columna especial inaugurada con el título "Los españoles en la Argentina". Es

6 DE INTERÉS para los españoles del Río de la Plata. ECE, Buenos Aires, p. 1, C2-3, 3 jul. 1887. 
interesante remarcar esta acción de ECE, por cuanto también formaba parte de una concepción de las funciones del diario, y del diarismo en general. Unos años antes de la aparición de la columna "Los españoles en la Argentina", el columnista Benigno Teijeiro Martínez afirmaba desde su editorial "Hombres y cosas de Galicia", que

La misión actual de la prensa periódica, como la del diarismo, es múltiple por lo mismo que son múltiples las fuerzas activas de la sociedad en que se radica, y por lo mismo que es tan vasta su misión, no deben olvidarse los aniversarios históricos y mucho menos el tributar culto homenaje a los hombres que honraron y honran la patria con su ciencia, con su arte o con su industria, que sólo así puede contribuirse a la transformación de la sociedad facilitándole conocimientos que retemplen el alma regional, para que surja más grande la idea de patria. ${ }^{7}$

Es interesante rescatar la presentación de esta nueva columna, ya en su nueva etapa como Sociedad Anónima desde 1903. También en este aspecto el diario buscó una línea de continuidad para otorgarle "un valor histórico" a esta iniciativa, y la encontrará en la Galería de los Españoles Ilustres, como vimos publicada por ECE en 1893 y 1894. Al respecto, los redactores del diario entendieron que había un "vacío" dentro de la institucionalización de la colonia, justamente por la ausencia de una historia propia y local, que venía a completar las tareas patrióticas de los españoles. En este sentido, la nota dice:

Cumpliendo uno de los propósitos expuestos por la Comisión organizadora de la Sociedad Anónima EL CORREO ESPAÑOL, en el manifiesto publicado en estas columnas, comenzamos hoy la que podríamos denominar segunda serie de la Galería de los Españoles llustres. La primera estaba dedicada a las figuras de primera magnitud de nuestra patria, cuyos nombres conserva la

7 HOMBRES y cosas de Galicia. ECE, Buenos Aires, p. 1, C5-6, 16 oct. 1901. 
historia. Dedicaremos la segunda a las personalidades notables que han pertenecido a la colectividad española en la República Argentina y a cuyos nombres no se ha consagrado todavía el público homenaje que merecen. Consagrárselo es el objeto de la obra que emprendemos: obra de justicia y de bien entendido patriotismo. Contribuyeron aquellos hombres al progreso moral y material del país que consideraron su segunda patria y honraron a la colectividad. Enalteciéndoles, nos enaltecemos todos. ${ }^{8}$

Dentro de las elites de la colonia española, existieron una serie de personalidades que, a pesar de no haber logrado el camino del ascenso social a través del éxito económico, tuvieron un lugar privilegiado entre sus pares. Este fue el caso de la elite intelectual, hombres del mundo de las letras que desarrollaron tareas de "periodistas" o escritores, aunque casi ninguno de ellos logró forjar una vida dedicada exclusivamente a la literatura. Estos personajes fueron centrales a la hora de prolongar una imagen sobre la colectividad, por cuanto les cupo la tarea de narrar una historia de sus pares en la Argentina. Sumado a esto, el lugar relevante que la prensa, y fundamentalmente los periódicos españoles desempeñaron en la constitución del "lazo social" entre los paisanos, depositaron en los redactores y periodistas españoles un aura de figuración, por otro lado, conquistado en base a su función de "nexos". En esta línea, a manera de ejemplo, queremos destacar a Manuel Barros, César Cisneros Luces, Bartolomé Victory y Suárez, Justo López de Gomara, todas figuras que fueron reivindicadas por el diario en diferentes oportunidades. ${ }^{9}$

Una vez establecidos los atributos salientes de aquellos que dejaron su estela en la constitución de la colonia, podríamos

8 LOS ESPAÑOLES en la Argentina. ECE, Buenos Aires, p. 4 completa, 10 abr. 1903. El subrayado es nuestro.

9 Al respecto ver: LOS ESPAÑOLES en Argentina (Victory y Suárez). ECE, Buenos Aires, p. 4, C3-4, 22 agosto 1903; LOS ESPAÑOLES en Argentina (Manuel Barros). ECE, Buenos Aires, p. 4, C3-4, 9 sept. 1903; CESAR Cisneros Luces. ECE, Buenos Aires, p. 1, C3-4, 8 enero 1897; PALABRAS a Cisneros Luces. ECE, Buenos Aires, p. 1, C4, 3 jun. 1897. 
englobarlos dentro de un cúmulo de virtudes: honradez, rectitud y laboriosidad, unida a una vida alejada de las atracciones de lo superfluo (juego, divertimentos alejados de la estricta moral dominante de la época). Debe agregárse además, para que se cierre el círculo de los requerimientos necesarios, una marcada vocación por la construcción de este lazo de unión tan mentado entre las elites de inmigrantes. Su participación en la sociabilidad de la época, también era un requisito fundamental para su consagración en el panteón de los apellidos notables: su aporte a las instituciones fundantes de la colonia. Hasta aquí sus requerimientos más destacados. Nosotros entendemos que además de estos elementos, debían necesariamente existir otros componentes, quizás atribuido ex post a todas estas figuras por parte de las elites intelectuales rioplatenses, encargados de erigir una historia propia, local, de los inmigrantes en estas playas. El primero que se desprende de los atributos mencionados anteriormente tenía que ver con el aporte de estas figuras al progreso de la República, en tanto agentes activos y generadores de bienestar. El segundo punto tenía que ver con un "nacionalismo español" intrínseco a la personalidad de todas estas grandes figuras, un nacionalismo que estaba por encima a su región de origen, en este sentido, una voluntad de construir naciones: el nacionalismo antes que la nación. Este atributo fue arrogado a estas figuras patricias, aún por encima de sus predilecciones identitarias, pero que fungieron como verdaderos vectores y componentes necesarios para el canon del indiano exitoso.

\section{Los nombres propios para las grandes gestas}

Seguramente en el intento de hilvanar un recorrido dentro del esquema propuesto, aparecerán muchos sucesos buscando una acción concreta, dispararon una serie de interpretaciones y de usos tendientes a exaltar una fibra nacional. Nosotros escogimos una serie de acontecimientos que creemos representativos de las editoriales del diario, por considerar que, transitando estas experiencias, ECE buscó magnificarlas más allá de su verdadera 
significación y sentido. En este punto, desde las acciones más pequeñas hasta las más dimensionadas, estuvieron orientadas a interpelar el subjetivismo de los paisanos, independientemente de si los resultados obtenidos se vinculaban con las expectativas originales. En definitiva, los discursos emitidos desde un diario, siempre, o casi siempre, nos hablaban más del emisor que del receptor del mensaje.

Lo significativo para nosotros será valorar a estos discursos e imágenes que circulaban entre los miembros de la elite intelectual y también sobre grupos de inmigrantes lectores del periódico. Para complementar el análisis, analizaremos cómo estos argumentos se verificaron en la materialidad de las acciones, lo que nos lleva a pensar al diario como un intermediario válido para la construcción de una historia local de la colonia española.

Al igual que los redactores de ECE, interpretamos al diario como un interlocutor privilegiado de al menos un sector muy importante de los inmigrantes españoles de la región. Esta construcción de una historia local puede verse también como una prolongación de la historia nacional dentro de la que ésta deseaba inscribe. El periódico desde sus columnas lo expresaba de esta manera:

La naturaleza física de cualquier cuerpo está sujeta a transformaciones, a series y a eclipses; y esto mismo acontece con un periódico. Nace para vivir y vive para terminar ineludiblemente su carrera. Múltiples circunstancias, empero, influyen en su existencia y entre ellas la honradez de principios y la santidad de las causas. Puede afirmarse que todo aquél periódico que ha logrado alcanzar algunos años de vida, responde a una necesidad, y tiene tanta razón de ser como los hechos más indispensables. Creación que logra por horizontes los espacios ilimitados de la inteligencia, y por base la moral universal y el aprecio del hombre, se aplastaría sobre sí misma al menor movimiento que estremeciendo su apoyo le fuese hostil.

¿Sucede esto acaso con EL CORREO ESPAÑOL, que entra hoy en su noveno año, tras ocho de resistir el oleaje de la pasión, de clavar 
el oriflama de su patria en la abrupta guarida de sus impugnadores, de unir y aproximar a sus representados y de hacerse intérprete de sus aspiraciones sin más fuerzas que su patriotismo y sin otras galas que la satisfacción del deber y la tranquilidad de una conciencia honrada, único lauro a que ha aspirado siempre ${ }^{10}$

Como una muestra de lo expuesto, rescatamos una acción concreta del diario y de su director para puntualizar la idea del periódico también como un mediador. Con motivo de la Asamblea que se realizó el día 8 de mayo de 1878, Romero Jimenez efectuó un llamado a la colonia para recibir el apoyo y el auxilio para su diario. Entre los valores más destacados estuvieron las acciones de ayuda y promoción que desde el diario se llevaron adelante y entre ellas, se destacó el caso de Juan Martínez Villergas. En esa oportunidad, el diario decidió emprender una solicitud de ayuda a través de una suscripción y de una velada literaria, para destinar los fondos recaudados hacia el Perú, lugar de residencia de Villergas. Estas gestas locales, como la de Villergas ${ }^{11}$, sirvieron para vincular, en tanto españoles, a los inmigrantes que se volcaron en su ayuda.

En este caso puntual, nos proponemos reconstruir esta ayuda que los españoles del Plata realizaron y que fue encabezada y principiada desde las páginas de ECE. La iniciativa también incluyó a los periódicos de la ciudad de Montevideo, fundamentalmente al periódico La Colonia Española (en adelante LCE) ${ }^{12}$. Durante el mes de noviembre de 1877, LCE publica una columna titulada

$108^{\circ}$ ANIVERSARIO de ECE. ECE, Buenos Aires, p. 1 completa, 29 jul. 1880. El subrayado es nuestro.

11 Juan Martínez Villergas (Valladolid, 1816 - Zamora. 1894). Crítico, literato y publicista español, fundador de célebres publicaciones en España y América Latina como El Tío Camorra (1847 - 1848) en Madrid; El Moro Muza en la Habana, Cuba y El emigrado en Lima, Perú. En Buenos Aires funda y dirige el semanario Antón Perulero, de gran repercusión durante los años 1874 y 1875.

12 Periódico consultado en la Hemeroteca de la Biblioteca Nacional de la República Oriental del Uruguay. 
"A los españoles" en donde hace mención a la delicada situación económica y físicas por las que atraviesa el distinguido crítico español, y en consecuencia la vida de Villergas, consagrada siempre al trabajo, es digna de toda protección. Y los españoles de la América del Sur tiene el honroso deber de buscar los medios y arbitrar los recursos para que aquel vate ponga fin a sus días en España.

Esta solidaridad regional que recoge LCE, fue reproducida por todos los periódicos españoles de la zona, y fue una iniciativa de ECE, como bien lo ilustra el diario español de Montevideo,

El Correo Español de Buenos Aires por intermedio de su Director y a impulsos de su abnegado corazón, donde no repercuten en balde los ecos de las desgracias ajenas, sin preocuparse de las propias, como un noble rasgo característico de su entereza y dignidad, ha iniciado en estas regiones la noble empresa a que se asocia de lleno LA COLONIA ESPAÑOLA. ${ }^{13}$

A partir de allí se comenzaron a publicar las listas de suscripciones, tanto en Buenos Aires como en Montevideo para juntar fondos que remitir hacia Lima.

Si como decía LCE, los españoles tienen un deber que llenar en estos momentos, desde Buenos Aires, Romero Jimenez dio comienzo a la campaña para auxiliar al escritor, siempre bajo la misma lógica argumentativa y de acción: no importaba el lugar de nacimiento de la persona en cuestión ni tampoco la región de España donde hubiese ocurrido la tragedia, los "españoles" debían auxiliar y solidarizarse con sus "hermanos en el sentimiento patriótico."

A los pocos meses de la aparición de la nota en el diario montevideano, ECE lanzaba la convocatoria a los presidentes de las sociedades españolas establecidas en la ciudad de Buenos Aires. Esta propuesta cristalizó luego en la velada literaria en honor a Martínez Villergas de la surgió la Corona poética en honor del

${ }^{13}$ A los españoles. LCE, Montevideo, p. 1, C2-3, 11 nov. 1877. 
eminente literato D. Juan Martínez Villergas de la que participaron los hombres de letras de la colonia. ${ }^{14}$

\section{ECE y el lenguaje como síntesis de una identidad nacional}

En esta sección, para completar este recorrido propuesto, analizaremos otra serie de iniciativas tendientes a generar y luego reforzar un aspecto central de la identidad nacional del siglo XIX: la cuestión del idioma. En ECE, la lengua castellana ocupó el lugar privilegiado en las páginas del diario y sus redactores se preocuparon por mostrar un uso del lenguaje muy castizo y de señalar aquellas desviaciones tanto en la escritura como en la fonética, cuando se trataba de otras lenguas regionales.

Vemos necesario recuperar la figura de Villergas, quien en el año 1876 mantuvo una polémica con Juan María Gutiérrez en torno al lenguaje y al cuidado de las formas discursivas. ${ }^{15}$ En el centro de la disputa dialéctica estuvo la importancia del idioma castellano y la centralidad de la lengua, como un vehículo para reafirmar una dominación cultural, al mismo tiempo que como un reforzamiento de la identidad nacional. Sin duda que esta figura literaria, uno de los poetas más fecundos y literatos más castizos de la rica fabla de Cervantes, como afirmaba LCE, nos daba la posibilidad de iniciar un análisis sobre el uso de la lengua castellana como lengua oficial y homogeneizadora desde las páginas de ECE. A partir de allí creemos encontrar en esta actitud, una pauta para aglutinar y legitimar un aspecto central

14 REUNIÓN. ECE, Buenos Aires, p. 1, C1, 5 feb. 1878.

15 Hacia fines del año 1875, Gutiérrez responde por carta al Secretario de la Academia Española rechazando el diploma que lo declaraba como miembro correspondiente de esa institución. Los motivos de esta decisión se fundaron en la concepción que Gutiérrez poseía de la lengua, y que tenía que ver con que no se podía estrechar los límites de la comunicación sobre parámetros que no aceptaran todos los neologismos y las influencias que en América se recibían de otras lenguas y culturas, dando paso a nuevas adaptaciones que tenían que ver con las realidades en donde el castellano sirviera de idioma oficial. 
del nacionalismo en el siglo XIX, la participación de los pueblos de una lengua común.

El idioma castellano fue central en la escritura de ECE. Todas sus columnas estuvieron escritas en el más perfecto tono castizo uniforme, señalando en letras cursivas todo tipo de desviaciones, tanto en la escritura como en las fonéticas cuando se trataba de reproducir los malos usos del lenguaje. Hubo sí espacio para algunos escritos en las lenguas regionales, pero siempre estuvieron reservadas al folklore del lugar, predominantemente cuando se publicaban poesías alusivas. Estas siempre estuvieron dentro de este margen reservado a las diferencias dentro de un orden, en donde el vértice principal era ocupado por el idioma castellano. Apoyándonos en las ideas de Juan B. Alberdi, cuando le tocó participar del debate alrededor del predominio del castellano en América, pensamos que esta tendencia era una opinión consensuada dentro de las elites intelectuales:

(España) ¿qué puede hacer hoy día para reparar ese mal en cuanto cabe? Muchas cosas, que están a su mano. Desde luego, abstenerse de trabar la emigración de los españoles que quieren ir al nuevo mundo. La población es el mejor conductor de los idiomas. Así se introdujo el castellano en América, y así se mantendrá fiel a su tipo original. Los españoles dan allí el ejemplo vivo de la bella pronunciación castellana. Su prensa, escrita con propiedad, ejerce un buen influjo en la prensa americana. ${ }^{16}$

\section{Centralidad del idioma castellano y su relación con las lenguas regionales}

Para nuestro análisis se abren dos aspectos que quisiéramos remarcar. El primero de ellos tiene que ver con la centralidad del idioma castellano en el periódico, en línea con lo reseñado de trasmitir una historia nacional con eje en castilla y de encumbrar figuras históricas de la península que a partir de allí se erigirían

${ }^{16}$ ALBERDI, op. cit. p. 36. El agregado y la cursiva es nuestro. 
como próceres para toda la nación. Esta fue sin dudas una política editorial homogeneizadora para con las otras regiones de España, y fundamentalmente para los inmigrantes gallegos, vascos y catalanes que poblaban la ciudad, y en muchos casos reivindicaban su idioma regional y a partir de allí, sus propias costumbres y culturas.

En su polémica epistolar con Villergas, Juan María Gutiérrez remarcaba esta particularidad de la inmigración española; justamente, la ausencia de una homogeneidad lingüística, dado que "y en esto que es histórico, práctico, de todos los días, que se oye por las calles y plazas, puesto que en plazas y calles se habla el catalán en español, ¿qué insulto cabe?" [...] "y debemos esperar que la organización privilegiada de los niños que beben agua del Plata convertirá en $d$ suave la $d$ forjada a yunque de sus maestros venidos del Llobregat."17

Con estas frases el escritor porteño remarcaba que esta pretendida homogeneidad lingüística en la que se insistía desde la península era impracticable, y desde ya, no deseada por buena parte de los escritores de América. En esta etapa del trabajo nos interesa puntualizar, no la idea de una independencia lingüística, sino el intento de ECE y sus redactores/escritores para constituir al idioma castizo como a un representante de un pueblo/nación, que involucrara a todas las regiones.

Observamos en este esfuerzo una práctica casi habitual de remarcar aquella pretendida centralidad para el idioma. No solo en la tarea de redactar el periódico, sino también en marcar y hacer notar cuándo alguien, escribía correctamente, utilizando perfectamente el castellano. Una muestra de ello lo observamos en la columna "Hombres y cosas de Galicia" que Benigno Teijeiro Martínez ofrecía asiduamente a los lectores. Esta columna tenía por objeto reivindicar a Galicia y sus logros, además de publicitar favorablemente ante lo que se experimentaba como un entorno

17 GUTIÉRREZ, Juan María. Carta tercera. En: Cartas de un porteño, 24 de enero de 1876. Edición de Ernesto Morales. Buenos Aires: Editorial Sudamericana, 1942. p. 54-55. 
crecientemente xenófobo. Más allá de su objetivo principal, a través de sus columnas nosotros daremos cuenta de esta preocupación por el uso del idioma.

Es así que el 31 de agosto de 1901, luego de disculparse ante los lectores por su ausencia debido a sus dolaimas, refiriéndose a sus dolencias, presentó el libro de D. Adolfo Rey titulado Saudades, Recuerdos y memorias de Marineda. La primera valoración positiva que Teijeiro Martínez hizo de la obra es que "Adolfo Rey tiene la chifladura de escribir, y escribe bien, hablamos de escribir correctamente y con propiedad, como lo manda la Real Academia; y por tal razón, en vano la crítica hallará en sus escritos donde hincar el diente."18

Este tipo de descripciones no podría dejar de llamarnos la atención sino fuera porque en esta época del cambio de siglo, cuando se escribe esta columna, la cuestión del idioma cobró una importancia nodal. Es allí donde el correcto uso del idioma castellano, fijándose a sus reglas y sus estilos, es un valor agregado a la obra y en la crítica de nuestro cronista, fue casi tan importante como el contenido del libro; las formas de la escritura obtienen para sí un lugar de privilegio. El análisis del capítulo "Historia vulgar" nos permite introducirnos de lleno, en lo que observamos una preocupación del columnista, devenido crítico. Allí nos previene afirmando que:

siendo del género realista, está salpicado de agudas e intencionadas frases gallegas, algunas tan naturalistas como ésta: ¿Hasmo dar, Sabela?; ¡Cando nos casemos, Xaniño! ${ }^{19}$

Si bien el libro nos cuenta los relatos costumbristas de la vida en Galicia, no deja de sorprender que lo señalado como particularidad y una nota distintiva sean las frases en gallego, y no las castellanas. Al ingresar en cada uno de los capítulos del

18 HOMBRES y cosas de Galicia. ECE, Buenos Aires, p. 1, C6; p. 2, C1, 31 agosto 1901.

19 El subrayado es nuestro. 
libro, estas observaciones se repiten, como en el apartado "El regreso a la patria, Alejandría y Aficiones" dado que:

son notables descripciones en las que el realismo se reanima con lo correcto de la frase, aunque las más de las veces recargada de extranjerismos innecesarios en nuestra riquísima lengua castellana; en cambio le dan más vigor y gracia, más vida y animación, el intercalado de las frases gallegas, porque difícilmente podrían expresarse con tanto mimo en otra lengua. Como quiera que sea y en descargo de la crítica, es forzoso confesar que los expresados capítulos se leen con gusto, hasta con fruición. ${ }^{20}$

Si estos extranjerismos de los que se valió el autor, son innecesarios al sentir de nuestro editorialista, no lo son sin embargo, las entradas en gallego, dado que, difícilmente podría expresarse con tanto mimo en otra lengua. Esta composición de lugar de cada una de las lenguas se entiende dentro de la convivencia necesaria entre el castellano a las lenguas regionales. Sin embargo, no debe haber interrogantes sobre el espacio que a cada una le cabe. Para este tipo de debates, el 11 de febrero de 1903 ECE publicó una columna titulada "Lenguas y dialectos", cuya firma con seudónimo se adjudicó Don Ramiro. Allí el autor de la nota especifica que:

no hay otra categoría en las lenguas que la que establece su mayor o menor cultura; porque las hay no cultivadas ni escritas; en boca sólo de gente rústica e iletrada, escasas de vocablos, giros y modos de expresión, incapaces de formular conceptos que no sean sencillismos y elementales; y las hay, al contrario, cultísimas, enriquecidas con voces tomadas de las lenguas madres y de otras extrañas antiguas y modernas, empleadas de largo tiempo atrás por sabios, filósofos y pensadores profundos. Estas últimas estarán en lo alto de la escala y aquéllas en lo bajo, sin que haya de tenerse

20 HOMBRES y cosas de Galicia. ECE, Buenos Aires, p. 1, C6; p. 2, C1, 31 agosto 1901 . El subrayado es nuestro. 
en cuenta en la clasificación que de ellas se haga que sean o no oficiales. ${ }^{21}$

Esta distinción en la pluma del autor deja en claro dónde se establecen las diferencias que hacen que una lengua ocupe un lugar de privilegio en la pirámide jerárquica, éstas son las reglas y las normas que ayudan a darle a la lengua su riqueza y perfección, necesario para elaborar los más profundos pensamientos. Retomando a Don Ramiro, las reglas fijas de la lengua castellana, la colocaban en un lugar de superioridad:

el castellano, el portugués, el gallego y el vable (y lo escribo con v, por representar esa letra la f de fábula - fabla o habla - que es el vocablo latino de que procede) son dialectos, los cuatro de los más emparentados entre sí de todos los de la familia neolatina, pero los dos primeros son literarios, mientras que los dos últimos, y en mayor grado el vable, por haber sido poco escritos y haberse abandonado al vulgo, ocupan más humilde lugar en la escala de las lenguas. ${ }^{22}$

Estas lenguas literarias cultas y luego administrativas, a diferencia de aquellos dialectos regionales indisciplinados, como decía Don Ramiro, tenían una estructura codificada, y pesar de que estos temas fueran una arista exclusiva para los hombres de letras y los filólogos, aparecían en las columnas del diario introduciendo temas con el objetivo claro no sólo de instalar el castellano, sino también de ir perfeccionándolo en estas costas del Plata. Don Ramiro, esta vez desde una columna titulada El "le" y el "la", se ocupó de zanjar polémicas en torno a la utilización de los dativos, siempre en sintonía con el uso castizo del lenguaje.

En este artículo, que buscó marcar las características más castizas en el uso del lenguaje, se dejó constancia cuáles fueron los límites de lo que se entiende por Castilla, y a partir de allí el uso de la lengua castellana con sus modismos regionales, que

21 LENGUAS y dialectos. ECE, Buenos Aires, p. 4, C3-4, 11 feb. 1903.

22 Ibid. 
como vimos en notas anteriores fueron aceptadas, pero en una gradación de menor valía. Para el autor de la nota, la lengua castellana se desarrolló y adquirió carácter de literaria cuando estaba ya formada la monarquía de Castilla y alcanzó su apogeo cuando había sido llevada ya al otro lado del mar por nuestros navegantes y conquistadores. ${ }^{23}$ En consonancia a como veníamos analizando desde capítulos anteriores, junto con la nación española, también la lengua castellana comenzó a expandirse con Isabel La Católica, en esta expansión ya se contaban todas las regiones que constituían a comienzos del siglo XX el Estado Español. Para el autor de la nota, si bien no descalifica el uso de la en el dativo de ella, sostiene sin embargo que esa no es la forma más castiza de utilizarla, dejando en claro que existe cierto patrimonio lingüístico que era necesario preservar, más en las épocas en donde no estaba aún resguardado de los avances de los regionalismos dialectales;

por lo menos los nacidos y educados en Madrid, cuento la costumbre de emplear la forma la en el dativo del pronombre femenino ella, que tan desagradablemente suena en mis oídos y en los de la mayor parte de los que en el mundo tiene la lengua castellana por propia. Y la cuento como novedad, porque fuera de Quevedo y de alguno que otro autor de su tiempo, que tampoco la seguían invariablemente, no la hallo aceptada sino por escritores muy modernos. Y aunque ni me gusta, ni la acepte la Academia, me guardaré de censurarla. ${ }^{24}$

Esta expansión del castellano como lengua dominante y nacional, fue celebrada desde el diario desde el punto de vista de una necesidad creciente y también inevitable hacia la definitiva unión nacional. En la columna "Hombres y cosas de Galicia" Benigno Teijeiro Martínez evoca bajo la misma lógica a D. Juan Cuveiro Piñol. Este literato y filólogo gallego "amante de la lengua y de la literatura

${ }^{23}$ EL LE y el la. ECE, Buenos Aires, p. 4, C1-2-3, 19 dic. 1902.

${ }^{24}$ Ibid. El subrayado es nuestro. 
regionales, también dedicó sus ocios a escribir en prosa y verso y dotar a Galicia de un curioso Diccionario gallego castellano."25

En consonancia con el surgimiento de las historias regionales y el desarrollo de las literaturas provinciales, también se evidenció la necesidad de codificar sus lenguas. Este fue el aspecto valorado por ECE para el caso de Cuveiro Piñol, sumado a su tarea de unir y vehiculizar la conexión entre el gallego y el castellano a través de las escrituras de los primeros Diccionarios a mediados del siglo XIX.

Otra de los acercamientos explorados fue la dedicada a vindicación de las glorias literarias. Tomando en consideración la afirmación de Juan María Gutiérrez en sus "Cartas de un porteño", el alma de los pueblos se expresa en su literatura, las evocaciones del diario hacia sus literatos no podían estar ajenas a este apartado.

De esta manera, Miguel de Cervantes Saavedra, el príncipe de nuestra lengua, ocupó un espacio en la columna publicada el 23 de abril de 1878, con motivo de un nuevo aniversario de su muerte. Cervantes, uno de los puntos más significativos de la nacionalidad española, a la par de ser la mejor muestra del idioma castellano, simbolizó también el triunfo del progreso contra la oscuridad del orientalismo y del pasado medieval. ${ }^{26}$

Sus participaciones militares gloriosas lo encontraron vencedor del islamismo, y al mismo tiempo en que la Corona de Castilla comenzaba su empresa conquistadora y civilizadora, el idioma castellano se entronizaba como la lengua dominante, ya que se la alineó con el progreso. En esta operatoria argumental, Cervantes fue el estandarte más notorio, un quiebre y a la vez un punto de partida, del la nacionalidad española y su imperio. La literatura castellana se convierte en nacional, a partir de del siglo XVI,

cuando la Edad Media apenas alentaba bajo el peso de los descubrimientos y bajo la palabra inspirada de los reformadores; cuando el arte renacía y la literatura, con Shakespeare y Calderón,

25 HOMBRES y cosas de Galicia. ECE, Buenos Aires, p. 1, C5-6, 16 nov. 1901.

${ }^{26}$ MIGUEL Cervantes Saavedra. ECE, Buenos Aires, p. 1, C5-6, 23 abr. 1878. 
empezaba a despojarse de las tinieblas que durante quince siglos la estraviaron; cuando aquella sociedad empezaba a paladear los primeros sabores de una literatura nacional, aparece la obra inmortal de Miguel de Cervantes Saavedra, del príncipe de nuestra lengua, y al golpe de su sátira se derrumba, para no levantarse más, aquella literatura romántica que había estraviado el gusto y hecho de la literatura un caos inmenso donde apenas lucía chispa de algún que otro genio. ${ }^{27}$

Realizando el mismo análisis que con las grandes figuras históricas y los notables locales, con la literatura podríamos replicar este esquema verificando que así como ECE y la prensa española toda, evocaban a las grandes firmas de la literatura peninsular, también trabajó sobre la publicidad de las "figuras locales" de la literatura española. Esta tarea, al igual que en los apartados anteriores, complementó la centralidad pretendida para el castellano, y lo dotó además de la legitimidad necesaria para exhibirla como el pretendido idioma de todos los inmigrantes peninsulares.

El caso de Juan José García Velloso, ganador del certamen literario en los Juegos Florales organizados por ECE, cumplían con este objetivo, quien como premio publicaba en primera plana sus grabados y sus producciones. Para noviembre de 1883, García Velloso nacido en la provincia de Navarra, obtuvo la máxima distinción con la creación de un canto, dedicado a la "Lengua Castellana”, temática propuesta por la dirección del diario.

Los redactores del diario publicaron el poema completo y además realizaron una semblanza de la trayectoria literaria del autor, que por ese entonces estaba residiendo en la ciudad de Rosario. La composición dividida en seis estrofas, recorre la historia de la península describiendo paso a paso las ocupaciones y conquistas del territorio, hasta llegar al siglo XVI, que junto con los Reyes, Colón y Cervantes, reforzaron la hegemonía de Castilla y de España en su conjunto.

El final de la composición poética, afirmaba de cara al futuro, lo que pretendemos encerrar como idea central en este apartado:

${ }^{27}$ Ibid. El subrayado es nuestro. 
la centralidad de la lengua castellana se encontraba en el corazón de España, en este caso, se mostraba como la condensación de una historia de grandeza y universalismo.

\section{Bibliografía}

ALVAREZ JUNCO, José. Mater dolorosa. La idea de España en el siglo XIX. Madrid: Taurus, 2001.

GUTIÉRREZ, Juan María. Cartas de un porteño. Buenos Aires: Editorial Sudamericana, 1942. (Edición de Ernesto Morales).

INMAN-FOX, Edward. La invención de España. Nacionalismo liberal e identidad nacional. Madrid: Cátedra, 1997.

NÚÑEZ SEIXAS, Xosé Manoel. Los nacionalismos en la España Contemporánea (siglos XIX y XX). Barcelona: Hipótesis, 1999

PORTILLO VALDÉS, José María. Nación. En: FERNÁNDEZ SEBASTIÁN, Javier; FUENTES, Juan Francisco (dirs.). Diccionario político y social del siglo XIX español. Madrid: Alianza Editorial, 2002.

REVISTA HISTORIA SOCIAL, Valencia, n. 40, 2001. Número especial La construcción imaginaria de las comunidades nacionales.

\section{Fuentes secundarias}

CARRILLO SÁNCHEZ, Rafael. Galería de los españoles notables. Buenos Aires: Imprenta, Litografía y Encuadernación de Stiller \& Laars, calle San Martín 169, 1887.

EL CORREO ESPAÑOL. Buenos Aires.

LA COLONIA ESPAÑOLA. Montevideo.

Recebido em julho de 2016. Aprovado em janeiro de 2017. 